\title{
Adoption of new technologies or management systems on sheep and beef farms
}

\author{
D. C. SMEATON and A.E. DOOLEY \\ AgResearch Ltd, Ruakura Research Centre, Private Bag 3123, Hamilton \\ duncan.smeaton@agresearch.co.nz
}

\begin{abstract}
Adoption of new technologies or management systems on sheep and beef farms is a complex business. Multicriteria decision making (MCDM) methods provide a quantitative means to assist with decision making where there are multiple and conflicting goals measured in different units. The MCDM process consists of a series of stages from defining the problem to identifying the best alternatives. In a study investigating the adoption of beef production technologies, seven sheep and beef farmers from throughout New Zealand were confronted with a choice of improved or new systems for their beef production operations. Suggested systems had gross margin values calculated for them. The MCDM tool was then used to rank the new systems in order of preference. The farmers decided what criteria were important to them in making decisions. They then scored each system for each of the criteria, and decided on the importance of each criterion relative to other criteria. An overall ranking for each system was calculated using this information. Across all seven case studies, profit and issues directly related to profit made up less than half of the contribution to the top ranked system. In two cases, it contributed less than $20 \%$ of the total. Other criteria included sustainability, management complexity, labour requirements, family needs, impacts on pasture quality control and input costs risk. In nearly half of all cases, the most profitable option was not the preferred option when all criteria were considered.
\end{abstract}

Keywords: multiple criteria decision making, farm systems, beef, decision making

\section{Introduction}

Multiple criteria decision making (MCDM) methods provide people with a quantitative means to assist with decision making where there are multiple and conflicting goals measured in different units. Some of these goals are not easily measured; e.g. the importance of lifestyle. Other advantages of MCDM can include: making a decision more transparent to others, providing a means of problem structuring and working through the information, providing a focus for discussion, and helping people better understand a problem from their own and others' viewpoints. Although MCDM is increasingly used in Europe and USA, it has not been widely used in agricultural and environmental decision making in Australia and New Zealand (RAC 1992).

\section{The MCDM process}

There is considerable literature on MCDM techniques and their mathematical analysis. Generally the MCDM process is similar for all approaches (Dooley et al. 2005), but there are differences in the way the information on alternatives, criteria and relative significance of the criteria are elicited, specified and analysed (DTLR 2001; Belton $\&$ Stewart 2002).

The alternatives describe the systems or technologies about which the individual is trying to make a choice. The multiple criteria are the items which the individual applies to judging or choosing a particular alternative. Two example criteria include profit, which can frequently be measured objectively (\$) and "impacts of an alternative on family life" which is scored subjectively. Subjective criteria are handled in the MCDM process by giving a score on, for example, a 1 to 5 scale.

The next step is to weight the importance of the various criteria used. Using the example above, person $\mathrm{X}$ may decide that profit is five times more important to them in deciding on alternatives than impacts on family life. Person Y may decide that impacts on family life are irrelevant because all the alternatives are likely to have a similar impact on this criterion so that it is not a factor worth including in their decision making. Instead, they may decide that the "impacts of the various alternatives on the environment" are quite important in their decision making but they will accept limited damage if something is really profitable. And so the process continues.

The MCDM process we used (Dooley et al. 2005) incorporates the above to calculate a utility value or index for each alternative system about which a choice decision is required. The alternative which achieves the highest utility score, often expressed as a percentage of a maximum value, is the one that is likely to be adopted. The process may be repeated as information is reevaluated or as more information becomes available. The stages in the MCDM process are summarised in Figure 1.

This paper reports on the MCDM process and its usefulness. It was part of a wider question "why do not more farmers adopt seemingly profitable cattle technologies?"

\section{Methods}

In this project we applied the MCDM approach to seven 
Figure 1 The MCDM Process.

1. Define the problem and identify the decision maker's situation to guide the MCDM approach.

2. Identify decision making criteria

3. Identify the alternative systems or options available.

4. Measure or score criteria for each alternative, set maximum, minimum values

5. Apply importance weights to the criteria.

6. Run the model to calculate utility scores and select best alternative. Evaluate, change and re-run if desired

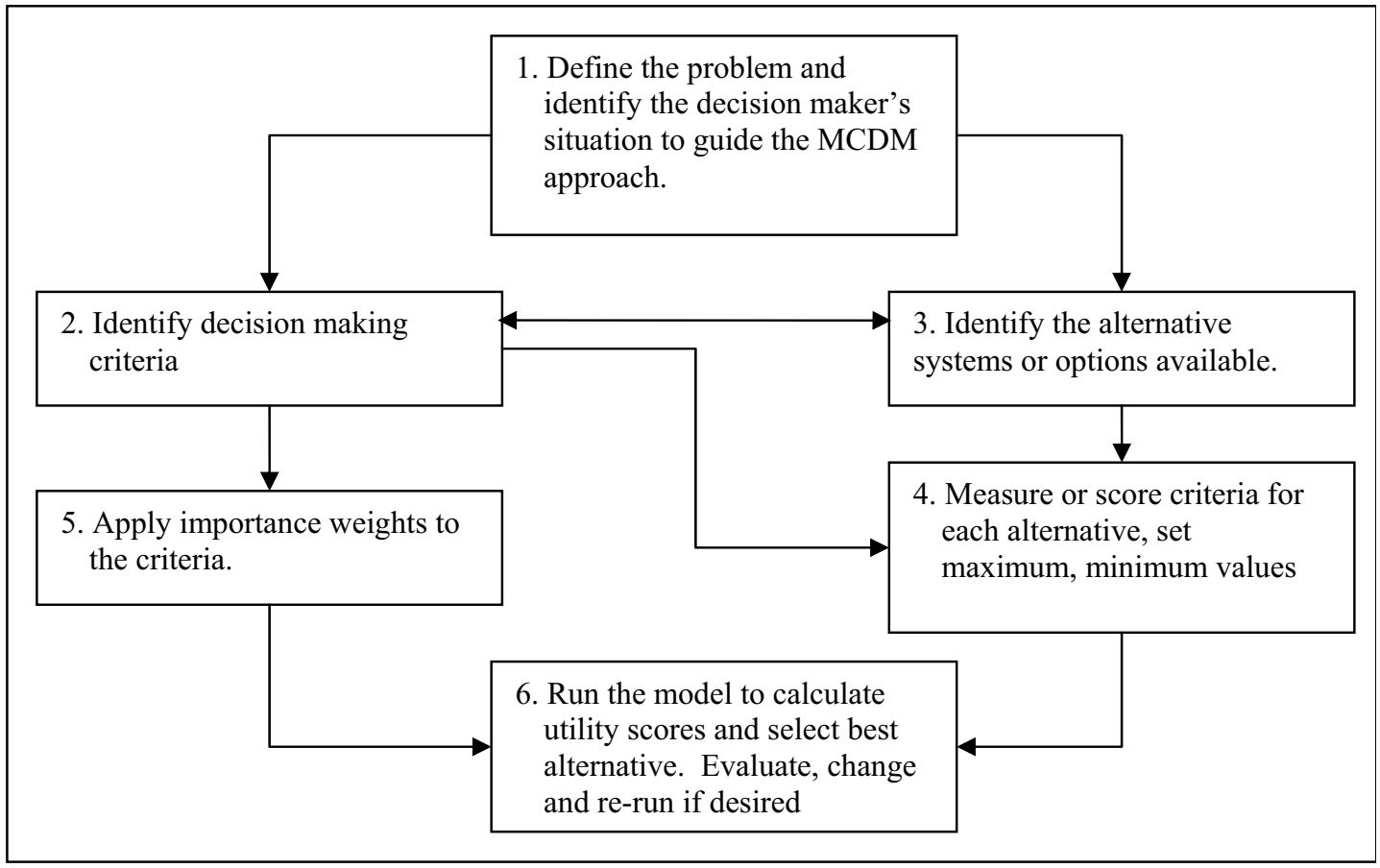

sheep and beef farmers using a case study approach. As part of another project, the farmers were in the throes of deciding on changing aspects of their farm systems and MCDM was used to assist them with these decisions. An MCDM model designed by Dooley et al. (2005) was used, including a spreadsheet template which was developed in Microsoft Excel.

\section{Case study farmers}

Of the seven case study farmers, three were looking at breeding cow policies, and four were considering beef finishing systems on hill country. Two of the farms were located in the South Island and five in the North Island. In all cases except one, the farmers were owner-operators. The exception was the manager of a large Maori trust farm. Farm size ranged from 400 to 2800 ha effective area.

\section{MCDM process; mentor groups}

Called focus farms, each of the above farms had a mentor group associated with it. These mentor groups consisted of 10 to 14 people, mostly local sheep and beef farmers with two to four rural professionals usually included.
The mentor group helped to identify possible beef systems for further discussion and possible criteria and the MCDM process was explained to them. The research team calculated the profitability of alternative systems using the computer programme called Farmax.

The number of possible combinations of alternative systems was large. However, previous discussions about the systems by the mentor groups associated with each focus farm and profitability analyses reduced the number of systems down to 10 or less. A base or current system was always used for comparison. Descriptions of each alternative system considered by the farmers are not provided in this paper except for illustrative purposes. In general terms, they included changes such as: sheep to cattle ratios, finishing to breeding stock ratios, young vs. older finishing cattle systems, slow vs. fast finishing liveweight gain pathways, different finishing cattle sexes, levels of nitrogen use, yearling heifer mating, calving date, cow breed and stocking rate.

\section{MCDM analysis (individual farmer decision making)}

The final stages of the MCDM analysis, including selection of criteria used, were conducted with the farmer, 
in the company of a research person who was able to provide guidance and clarification. However, it was made clear to the farmer that all criteria selection and weighting decisions were ultimately theirs as they were responsible for the decision making on that farm. The farmer had the option of rejecting some alternatives out of hand if they wished.

At each MCDM "session" the farmers readily accepted most of the alternatives arrived at as described above. In a couple of cases, they added a further alternative for consideration or deleted an alternative. A template of criteria was provided to the farmer, based on the researcher's previous observations and mentor group discussions. Farmers readily accepted this as a starting position in deciding on their own criteria prior to the analysis. Criteria the farmers decided on varied between individuals but often included some or all of: profit (short and long term), risk (production and financial), system complexity, benefits to other stock, labour requirements, family life, pasture quality in summer, winter demand, management system, woody weeds, and water quality. Ten to eleven criteria were identified in each case study.

The farmers then decided on a scoring system for the subjective criteria, usually on a 0 or 1 to 5 scale and gave scores for each alternative system for that particular criteria. They then weighted the relative importance of the criteria by giving them "swing values" (Dooley et al.
2005). An important additional decision the farmer had to make before running the programme, was to decide on a possible best and worst score or value for each criteria.

The criteria scores, measures and weightings were aggregated by the model and a utility value (out of $100 \%$ maximum possible value or index) was calculated for each alternative. This was presented in a graph. The farmer had the opportunity to re-assess and discuss the result with the researcher and revise the criteria scores and criteria weighting values if they wished.

\section{Results and Discussion \\ Understanding the process, time commitment}

With the seven case study farmers, the MCDM process or total "appointment" time took 2 to $2 \frac{1}{2}$ hours. This included understanding how the process worked, deciding on the alternative systems to be evaluated, criteria to be used, scoring systems including maximum and minimum values, assigning scores or values to the criteria and then assigning weightings to the criteria. After the first set of results was calculated, the farmers were able to discuss and revise the different criteria values and weightings.

Although the participants' initial reaction to MCDM was that it seemed complicated, once they saw an example output, they quickly grasped the concept. They had little

Figure 2 The various criteria selected and their frequency of use by the seven farmers for their MCDM runs.

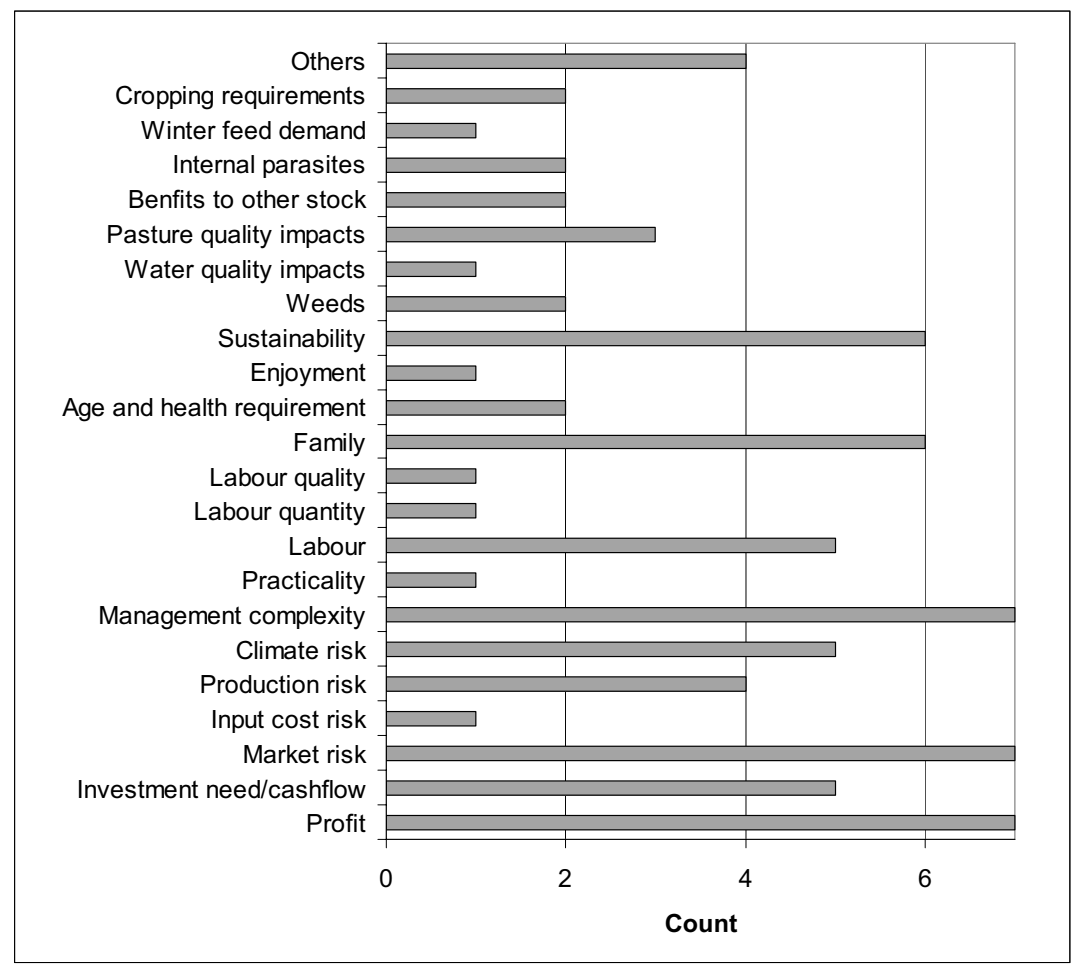


hesitation about allocating weightings and scores and accepting the results. The most difficult aspect of the analysis identified by participants was in understanding the criteria weighting method. Questions were not raised about the MCDM methodology itself, although there was discussion about the results and further analysis in most cases e.g. revision of the weights and scores, especially when the initial output was counter to intuitive expectations.

\section{Criteria used by farmers}

Figure 2 provides a profile of the criteria used by the seven farmers and the frequency with which they were used. Note that just because a farmer did not include, for example, family life as a criterion, this did not mean they did not care about family life. It may just mean that they expected all alternatives to have a similar effect on family life, thereby eliminating this as a factor in choosing between alternative systems.

Figure 3 shows examples of the weighting or swing value that two individual farmers placed on each criteria to determine the importance of that criteria in the decision making process. Farmer F5 clearly placed a lot of importance on profit relative to the other criteria they used in making decisions whereas farmer F7 placed fairly equal emphasis on all the criteria he used.

\section{Impact of criteria scale relative to their maximum and minimum values}

The farmer participants needed to understand the importance, not only of the criteria scoring systems used, but also of the effects of the maximum and minimum values that were applied vs. the effective scoring range. If the effective scoring band was narrow relative to the maximum-minimum range, then different scores between alternative systems within criteria were trivialised. Conversely, a narrow maximum-minimum range relative to the effective scoring band had the effect of scaling up the differences between alternative systems. This effect was quite separate from the weighting effects applied to the criteria.

\section{Utility scores for alternative systems}

Figure 4 shows a utility graph or summary output for farmer F2. He compared six alternative systems versus his base or status quo system. In addition, he considered that 10 criteria were important in making the decision about which alternative he would adopt.

The left hand side of the top bar in Figure 4 shows that profit and capital/cash flow/investment made up nearly $50 \%$ of the total maximum possible utility contribution, with eight other criteria contributing the rest. Among these eight, the consistent narrowness of the contribution "bands" for some criteria indicated they were not having much impact on the utility value of the alternative systems. All options tested performed better than the base system with "ewes" and "once-bred heifers" coming out on top. Even so, there was not a lot separating the seven alternatives. Note that the alternative system called R1yr Bulls, although of similar profitability to the most profitable ewes alternative, ranked nearly bottom on the utility scale and therefore would have a low likelihood of adoption.

Figure 5 shows a utility graph for farmer F4. For this farmer, the optimum option, "no cattle, sheep only" reached $62 \%$ of the maximum utility value possible. Two other systems came in very close to the best one, including the base with breeding cows system and the alternative

Figure 3 Weightings placed by two example farmers on criteria used in making decisions about alternative systems.

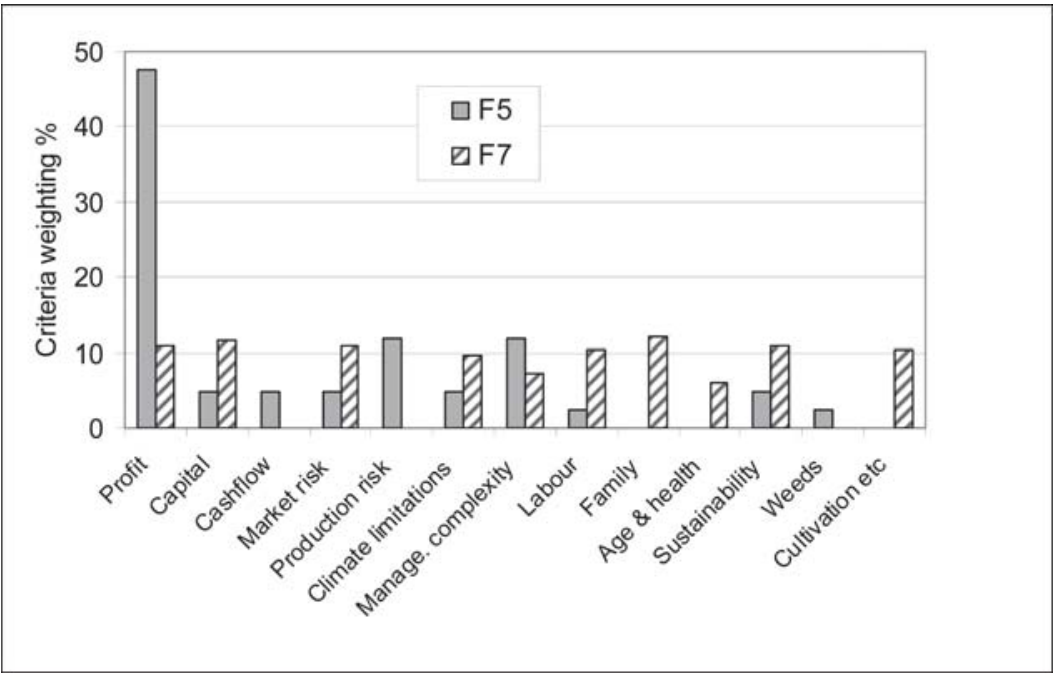


Figure 4 Utility values for alternative systems considered by farmer F2. Note that maximum is a hypothetical alternative "system" that scores "best" on all criteria.

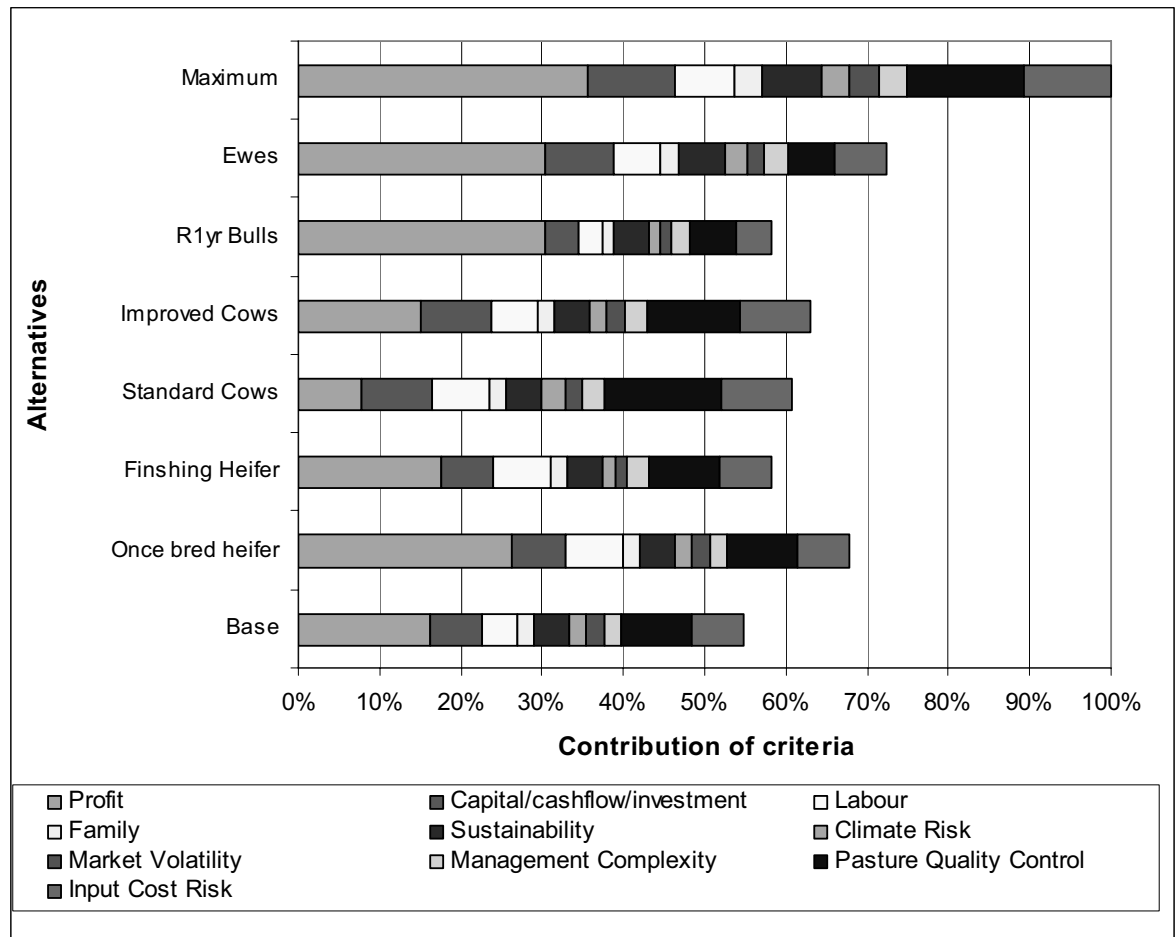

Figure 5 Utility values for alternative systems considered by farmer F4

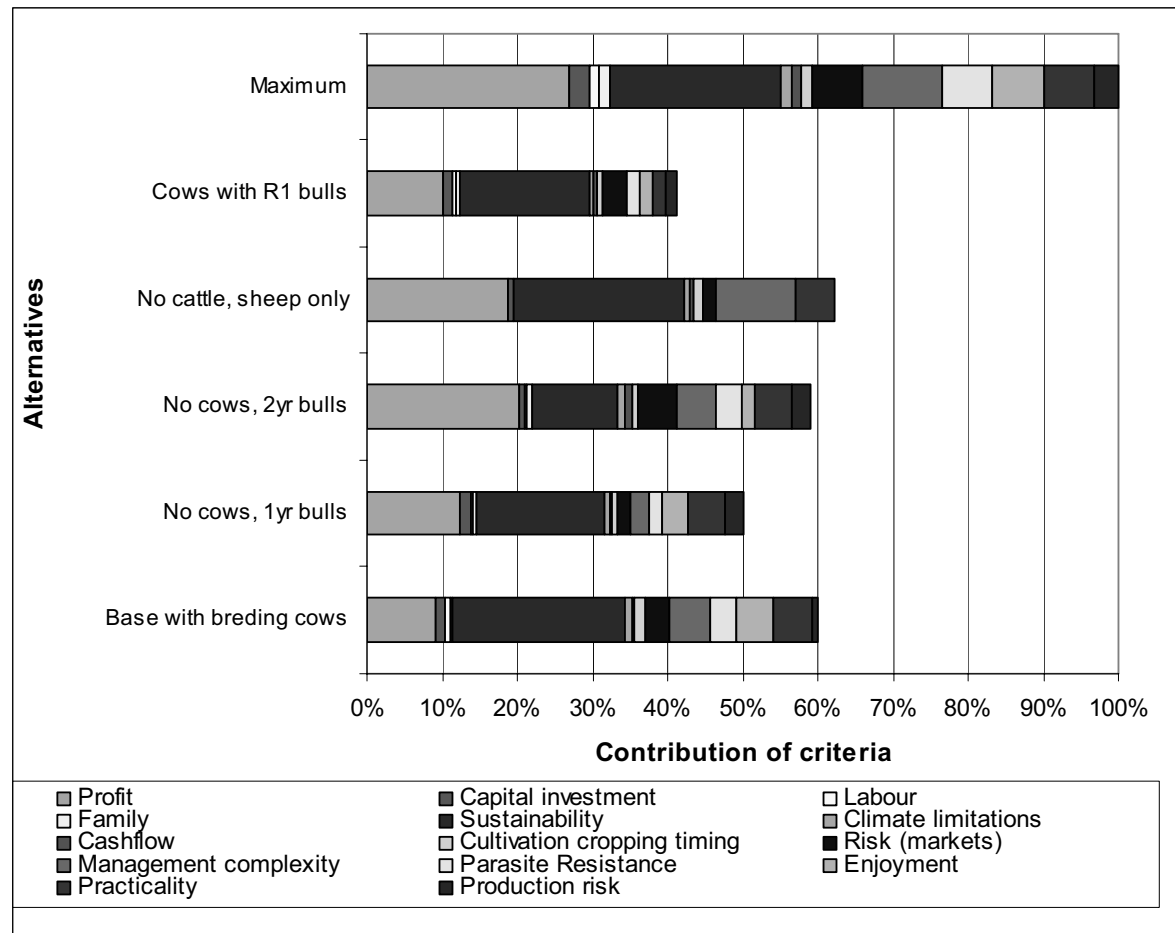


finally chosen for adoption; "no cows, 2 yr bulls". The criteria that had the biggest impacts on adoption decisions were profit and sustainability (Fig. 5). Risk (markets), management complexity, parasite resistance, enjoyment, practicality and production risk had an intermediate effect. Five criteria (labour, family, climate limitations, cash flow and cultivation cropping timing had only a very small impact on utility values. This is because F4 gave them low weighting or swing values (only $5 \%$ ) compared to the two most influential criteria which had weightings of 100 and $85 \%$ respectively. In addition, although he scored these criteria on a scale of range 1 to 5 , actual values assigned were in a narrower range so that their influence was small and consistent across alternatives.

Although the alternative called "base with breeding cows" had the second lowest profitability out of the alternatives considered it came close to being the most preferred system. This was because, for this farmer, it scored very well on the highly influential sustainability criterion and was intermediate for most of the other criteria (risk, markets, management complexity, parasite resistance, enjoyment, practicality).

\section{Contribution of profit to farmer decision making}

An important feature of the above results was the rather modest contribution of profit to the decision making process. Profit was often the most important component of decision making (as the research team expected) but was not dominant enough to control the outcomes (Figs. $4 \& 5$ ). Frequently, the most profitable system was not the highest scorer in the utility graphs because of the moderating influences of other criteria. Researchers frequently anticipate that farmers are motivated almost solely by profit. This leads to the expectation that, for example, a simple technology like yearling heifer mating will be adopted by the vast majority of farmers running breeding cow herds. However, despite the fact that the technology has been promoted for 30 years and has generally proven to be profitable, at present only $30 \%$ of farmers use the practice (Hickson et al. 2006). Clearly, farmers are invoking criteria other than profit in making this decision. Researchers and other promoters of technologies that should "be good for farmers" must recognise this when promoting their ideas. A benefit of the MCDM process was that it highlighted this issue and allowed the farmers to realise that it is "OK" to invoke these other frequently non-financial criteria when making decisions.

\section{Value of MCDM to the farmers, expectations and outcomes}

The MCDM tool was assessed relative to the farmers' expectations of its usefulness in assisting them with their decision making. They were asked for their opinions on: the appropriateness of MCDM for the decision; the importance of some of the benefits of MCDM methods; and whether the decision arrived at was what was intuitively expected (Evans \& Riha 1989; Hobbs et al. 1992; Gundersen et al. 1994; Zapatero et al. 1997; Qureshi et al. 1999; Bell et al. 2001; Lai et al. 2002).

The case study farmers agreed they had multiple conflicting goals which were therefore suitable for MCDM analyses. They were relatively satisfied with the results although as shown above, they did not always adopt the optimum outcome as defined by the figures showing utility values. Three explanations for this could be:

1. The MCDM model criteria and scoring systems had not been refined and revised enough to truly capture all the components that the farmer ultimately used in making a decision

2. New information came to light after the MCDM analysis which influenced the farmer's ultimate decision

3. Further thinking by the farmer as a result of the MCDM process caused him to re-assess and revise his views about the different alternatives.

If the purpose of the MCDM process was to predict the farmers' intuitive choice, the process could be criticised in that the farmers were allowed to evaluate the results and then go back, make adjustments to the criteria scores and their weightings and have another look at the results. Obviously this could be repeated until the farmer got the result they liked. However, all the farmers agreed that this process was useful to them and helped them to identify the criteria that were important to them.

\section{Learning and understanding, adoption of MCDM on a routine basis}

MCDM is perceived to be a decision making process or tool. Learning per se, is not generally seen to be its end purpose, as it is in extension activities. However, Belton and Stewart (2002) suggest learning could be the principal aim of an MCDM analysis. MCDM helps people understand a decision, and their own or others perspectives, thereby assisting them in identifying a preferred course of action. The interactive process used and visual presentation of results can assist participants with learning.

Most participants liked the structured approach, finding it helped them to think through and understand the decision. However, the research team did not see farmers using the formal spreadsheet model on a routine basis. A benefit of the MCDM process, however, was addressing the notion that farmers intuitively or subconsciously take account of multiple criteria in their decision making anyway. Presentation of the MCDM process to eight field day audiences throughout New Zealand during 2005 
was favourably received with good debate achieved about the results and use of the process. Our contention is that this, and the learning of the individual farmer about his decision making, was its most useful output. Clearly though, the case studies were required to produce the example utility graphs that we put in front of the above audiences for discussion. The process was also successfully used elsewhere by Dooley et al. (2005) to assist in making decisions in the face of heightened pressures from environmental constraints.

If MCDM is to be used in a structured manner, key points to ensure it is used successfully include:

- Ensuring that decision makers are prepared to invest time in the process

- Making sure at the beginning that the problem, MCDM decision process, technologies and any pre-defined decision alternatives are understood

- Investing time and commitment to identify criteria and alternatives, especially where these are not pre-defined or when dealing with unfamiliar technologies

- Realising that not everyone will necessarily be happy with the decision process because of differences in personality, background, objectives and expectations

- Realising outcomes will differ because of differences in perspectives.

The last point above needs emphasis. Individual farmer decision making truly is an individual process. We found that different individuals, when confronted with the same set of alternative systems to choose from will build different utility summary graphs, even though they may have been provided with the same system profitability information. This is because they will likely choose different criteria, each with their scoring systems and weightings in the utility calculations. Researchers and other people hoping to influence farmers for their own or the community's good must recognise this and develop technologies and systems that appeal to farmers, taking a range of possible criteria into account. It seems that farmers make decisions about alternative systems where profit as a criterion may contribute only a quarter or even less of the total influence on the decision made. This surely helps to answer our initial question "why do not more farmers adopt seemingly profitable cattle technologies?"

\section{ACKNOWLEDGEMENTS}

The authors wish to thank the seven farmers who took part in the MCDM process. Assistance from the science members of the beef production project is also gratefully acknowledged as is critical comment from colleagues and the mentor groups associated with the beef project.
Meat and Wool New Zealand funded the beef production project. With out their contribution, this project would not have been possible. An AGMARDT post-doctoral fellowship which allowed the MCDM spreadsheet model to be built is also gratefully acknowledged.

\section{REFERENCES}

Bell, M.L.; Hobbs, B.J.; Elliott, E.M.; Ellis, H.; Robinson, Z. 2001. An evaluation of multi-criteria methods in integrated assessment of climate policy. Journal of Multi-Criteria Decision Analysis 10: 229-256.

Belton, V.; Stewart, T.; 2002. Multiple criteria decision analysis: and integrated approach. Kluwer Academic Publishers, Boston.

DTLR, 2001. Multi-criteria analysis: a manual. Department for transport, local government and the region. [Online] Available: http://www.dtlr.gov.uk/ about/multicritreria. [Retrieved 12 August 2002].

Dooley, A.E.; Smeaton, D.; Ledgard, S.F. 2005. Identification of important criteria in farm systems decisions around Lake Taupo. Pp 27-35 In: New Zealand Agricultural and Resource Economics Society, AERU No. 152.

Evans, G.E.;Riha, J.R. 1989. Assessing DSS effectiveness using evaluation research methods. Information and Management 16: 197-206.

Gunderson, D.E.; Davis, D.L.; Davis, D.F. 1994. Can DSS technology improve group decision performance for end users? An experimental study. Journal of End User Computing 72: 3-10.

Hickson,R.E; Morris, S.T.; Kenyon, P.R. 2006. Dystocia in beef heifers: genetic and nutritional influences. New Zealand Veterinary Journal: in press

Hobbs, B.F.; Chankong, V.; Hamadeh, W.; Stakhiv, E.Z. 1992. Does choice of multicriteria method matter? An experiment in water resources planning. Water Resources Research 287: 1767-1779.

Lai, V.S.; Wong, B.K.; Cheung, W. 2002. Group decision making in a multiple criteria environment: A case using the AHP in software selection. European Journal of Operational Research 137:134-144.

Qureshi, M.E.; Harrison, S.R.; Wegener, M.K. 1999. Validation of multicriteria analysis models. Agricultural Systems 62:105-116.

RAC, 1992. Multi-criteria analysis as a resource assessment tool. RAC Research Paper No. 6. March 1992. Resource Assessment Commission.

Zapatero, E.G.; Smith, C.H.; Weistroffer, H.R. 1997. Evaluating multiple-attribute decision support systems. Journal of Multi-Criteria Decision Analysis 6: 201214. 